\title{
Research on variable speed operation of static frequency converter for pumped storage units
}

\author{
Haoyuan $\mathrm{Li}^{1 *}$, Guanjun $\mathrm{Li}^{1}$, Bo Yang ${ }^{1}$, Liantao $\mathrm{Ji}^{1}$ \\ ${ }^{1}$ China Electric Power Research Institute Co., Ltd., Nanjing, Jiangsu, 210003, China
}

\begin{abstract}
Constant speed pumped storage unit is widely used, however it cannot adjust the input power when working in the electric mode, and cannot work in the best efficiency when the head of the reservoir changes greatly. Therefore, it is necessary to study and develop the variable speed pumped storage systems. This paper has studied on variable speed operation of static frequency converter for pumped storage units. Besides, development status of variable speed pumped storage system at home and abroad is investigated. Furthermore, classification and advantages and disadvantages of variable speed pumped storage system are also introduced, mainly including two typical variable speed pumped storage systems, i.e., doubly-fed variable speed system and full power variable speed system.
\end{abstract}

\section{Introduction}

Energy is one of the driving forces for human survival and social development. However, due to the limited reserves of traditional fossil energy and its pollution to the environment, the research and utilization of new energy and renewable clean energy are carried out. In particular, wind power and photovoltaic have made great progress. However, the difficulty of new energy integration and consumption has increasingly become a difficult problem for the development. In view of the needs of modern smart grid construction, power storage system has become an important part of smart grid construction, and pumped storage is one of the most economical ways to quickly store power on a large scale, and has gradually become an effective tool for modern power system management [1].

In static frequency converter (SFC) variable frequency start-up, thyristor based inverter is used to generate variable frequency $\mathrm{AC}$ power to start the storage unit, which is the preferred starting mode of large-scaled pumped storage power station [2]. The working principle of pumped storage power station, in a simple way, is to use electric energy to pump the water from the downstream reservoir to the upstream reservoir in the hydrological flood season or when the power resources are abundant (such as the low power consumption period at night or holidays). The surplus electric energy is stored in the form of potential energy of water, and then hydropower generation is carried out when the system has demand [3].

Generally speaking, pumped storage power station adopts constant speed pumped storage unit. When the constant speed pumped storage unit works in the electric mode, it cannot adjust the input power, so it cannot meet the requirements of the power grid to adjust the grid frequency quickly and accurately. However, when working in the power generation mode, the water level of the upper and lower reservoirs of the pumped storage power station changes at the same time, and the water head changes greatly. When the water head is different, the speed corresponding to the best efficiency of power generation is different. Therefore, the requirement of variable speed operation of pumped storage units is produced [4].

However, there is little research on variable speed pumped storage unit, and there has been non power station using variable speed pumped storage unit yet at home. In addition to the role of constant speed pumped storage units, variable speed pumped storage units also have the following advantages [5]-[8]: 1) Power can be adjusted under pump condition. Automatic frequency control (AFC) is used to improve the quality of power grid power supply. AFC is to maintain the stability of power grid frequency by adjusting the power absorbed or generated by the unit when the power grid frequency fluctuates. 2) The efficiency is higher under power generation conditions. Due to the speed regulation, the operation range of the turbine is close to the optimal operating condition of the turbine, and the weighted average efficiency of the unit will be significantly improved, especially under the low head condition and partial load condition; meanwhile, the range of speed regulation of the unit will be enlarged, and the efficiency of the low head condition and part of the load condition will be improved. 3) The operation range of the turbine is wider and the operation performance is improved. Due to the constant speed operation of conventional pumped storage power station, there are some problems, such as low turbine efficiency, increased cavitation, wear and vibration. The variable speed pumped storage unit can avoid the start-up device of pump condition, and cooperate with the frequency automatic control of power system, so as to expand the operating

lihy@epri.sgcc.com.cn 
head range of pump turbine and obtain the best performance index. The speed, precision, amplitude and response time of power regulation are greatly improved. Therefore, variable speed operation of static frequency converter for pumped storage units is studied in the paper.

\section{Development status of variable speed pumped storage system at home and abroad}

\subsection{Overview of variable speed pumped storage development at abroad}

The key equipment of variable speed unit, frequency converter manager, has developed from CYC to GTO or IGCT to IEGT. Since the $1960 \mathrm{~s}$, foreign hydropower industry has started the research and test of variable speed pumped storage units. Japan, Germany, Switzerland and other countries have a large number of doubly fed variable speed pumped storage units play an important role in power grid operation.

Japan is currently the country with the largest number of variable speed pumped storage units. From Kyushu, the southernmost part of Japan, to Hokkaido in the north of Yun, Hitachi, Mitsubishi and Toshiba have more than 10 power stations and 17 units, which belong to six major power companies and power supply companies. Among them, the unit with the highest speed (600rpm) is supplied by Hitachi Mitsubishi, and the unit with the maximum capacity (475MVA / 460MW) and the unit with the highest rated head $(714 \mathrm{~m})$ are supplied by Toshiba Company. Okawachi Power Station units supplied by Hitachi Mitsubishi Company (put into operation in 1993) and Okukiyotsu Pumped Storage Plant phase II units supplied by Toshiba Company (put into operation in 1996) have been put into operation for more than 20 years

In 1990 and 1995, Toshiba completed the commissioning of the units in Yagisawa and Okawachi power station with large capacity respectively. That is, before the first large-scale variable speed unit is put into operation, Toshiba Company has carried out research and development, design and manufacturing for at least 10 years. The first variable speed unit has been in operation for more than 25 years. At present, the IEGT inverter technology of Toshiba Company has been used in Kazunogawa Pumped Storage Power Station and Jingji Pumped Storage Power Station. The output power or input power of 400MW variable frequency speed regulation unit in Okawachi Power Station can be changed within 0.2s, which is $32 \mathrm{MW}$ or $80 \mathrm{MW}$.

The Gaojian Power Station put into operation by Hitachi Mitsubishi Company in 1993 is the first selfexcited variable speed unit in the world. That is to say, before the first variable speed unit was put into operation, Hitachi Mitsubishi has been engaged in R\&D, design and manufacturing for about 13 years. The first variable speed unit has been in operation for more than 22 years. The latest inverter technology of Hitachi Mitsubishi is GCT of U2 and U3 units in Omarugawa Pumped Storage Power Station.
Omarugawa Pumped Storage Power Station has 4 units, 2 sets of constant speed and 2 sets of variable speed. The unit capacity of constant speed storage unit is $300 \mathrm{MW}$ and the rated head is $646.2 \mathrm{~m}$. Aiming at the high efficiency and miniaturization of the pump turbine, the rated speed of the unit is $600 \mathrm{r} / \mathrm{min}$. The unit of Omarugawa Pumped Storage Power Station has the characteristics of rapid response, such as the time from static to full load is shortened from $5 \mathrm{~min}$ to $2.5 \mathrm{~min}$, the time to reach the rated speed is shortened by $47 \mathrm{~s}$, and the opening time of ball valve is shortened by $10 \mathrm{~s}$. At present, few pumped storage units in the world reach this level.

The speed range of two variable speed pumped storage units is 576-624 r/min. under the pumping condition, each unit can change the input force of $100 \mathrm{MW}$ within $15 \mathrm{~s}$. The automatic frequency tracking range of pumping condition is expanded from $270 \mathrm{MW}-340 \mathrm{MW}$ to $240 \mathrm{MW}-340 \mathrm{MW}$. The minimum input force of pumping condition is also extended from $252 \mathrm{MW}$ to $224 \mathrm{MW}$. Since the generator motor can operate at any speed within the allowable speed range, the grid connection time after unit startup can be greatly shortened.

In 1998, Andritz Company obtained the supply contract of $2 \times 331 \mathrm{MVA}$ constant speed synchronous generator motor and 2x340MVA asynchronous induction variable speed unit of Jingu Power Station, including the design and manufacture of control system of the whole unit. The variable speed unit was put into operation in October 2004

Voith Hydropower signed a contract with Portuguese customers in 2010 to provide 2 sets of 433MVA variable speed units with synchronous speed of $428.6 \mathrm{r} / \mathrm{min}$ for FRADES2 project. Goldisthal variable speed pump turbine in Germany is also supplied by Voith Hydropower.

The Grimsel 2 pumped storage power station in Switzerland (with a total installed capacity of $1125 \mathrm{mw}$ ) uses IGCT and other power electronic devices to convert the original fixed speed unit into a $100 \mathrm{MW}$ full power variable speed unit. The actual output can quickly follow the planned output, and good results have been achieved.

\subsection{Overview of variable speed pumped storage development at home}

There are one $15 \mathrm{mva}$ variable speed unit successfully put into operation in Gangnan Hydropower Station in 1968, which adopts variable pole speed regulation mode, and two $2 \times 11$ MVA variable pole variable speed units put into operation in Miyun Hydropower Station in 1975. In addition, three $3 \times 98 \mathrm{MVA}$ variable frequency and variable pole pumped storage units were successfully put into operation in Panjiakou Hydropower Station in 1991, and three $3 \times 6.5 \mathrm{MVA}$ variable frequency speed regulating units were put into operation in 2010 in Xinjiang Yili Hydropower Station.

In China, large capacity variable speed pumped storage technology based on doubly fed system is being studied and put into practice. The first variable speed pumped storage power station will be put into operation at Fengning Pumped Storage Power Station in Hebei Province, and connected with Zhangbei VSC-HVDC to 
jointly solve new energy consumption and balance grid fluctuation. In the 2022 Beijing Winter Olympic Games, it will provide strong power guarantee for the Olympic Games.

Hebei Fengning Pumped Storage Power Station is led by the largest scale under construction in the world and the first introduction of two AC excitation variable speed units in China. A total of 12 sets $300 \mathrm{MW}$ reversible pump turbines and generator sets are installed. The total investment of the two phases is 19.237 billion RMB. It is planned that the first unit will generate electricity in 2021 and all 12 units will be put into operation in 2023 .

\section{Classification, advantages and disadvantages of variable speed pumped storage system}

There are two types of variable speed units in pumped storage power station

1) Gear shifting (generally two gears): including pole changing speed changing and double rotor double stator speed changing. The variable pole speed regulation mode is mainly used to change the pumping power when the water head changes greatly, and the electric mode cannot automatically control the frequency; some units basically operate according to the fixed speed unit, which plays a very limited role in the power grid and obtains economic benefits. The capacity is too small and the harmonic loss is large. In a word, the application of gear shifting is limited and difficult to be popularized.

2) Continuous speed regulation mode includes double fed frequency conversion speed regulation and full power frequency conversion speed regulation.

\subsection{Doubly fed variable speed pumped storage system}

The electrical connection diagram of doubly fed variable speed pumped storage system is shown in Fig. 1. The unit adopts doubly fed induction motor. The stator side is connected to the power grid, the rotor side is connected to the frequency converter, and the other end of the frequency converter is connected to the power grid. Since the inverter only undertakes slip power, the installed capacity only accounts for $20 \% \sim 30 \%$ of the total installed capacity, and the input power adjustment of the unit can reach $30 \%$, and the cost and land occupation are relatively small.

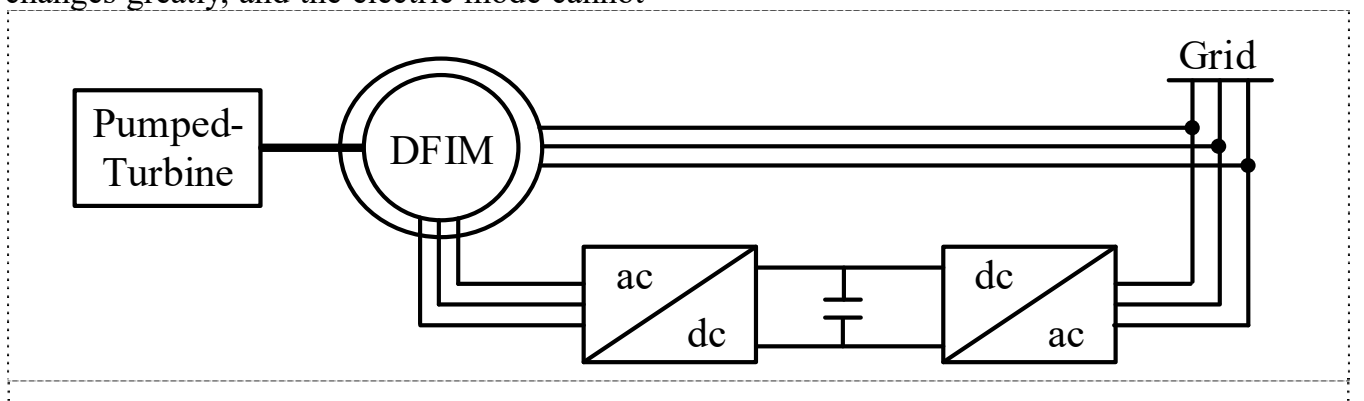

Figure 1. Connection diagram of doubly fed variable speed pumped storage system.

The control schematic diagram of doubly fed variable speed pumped storage system is shown in Fig. 2.

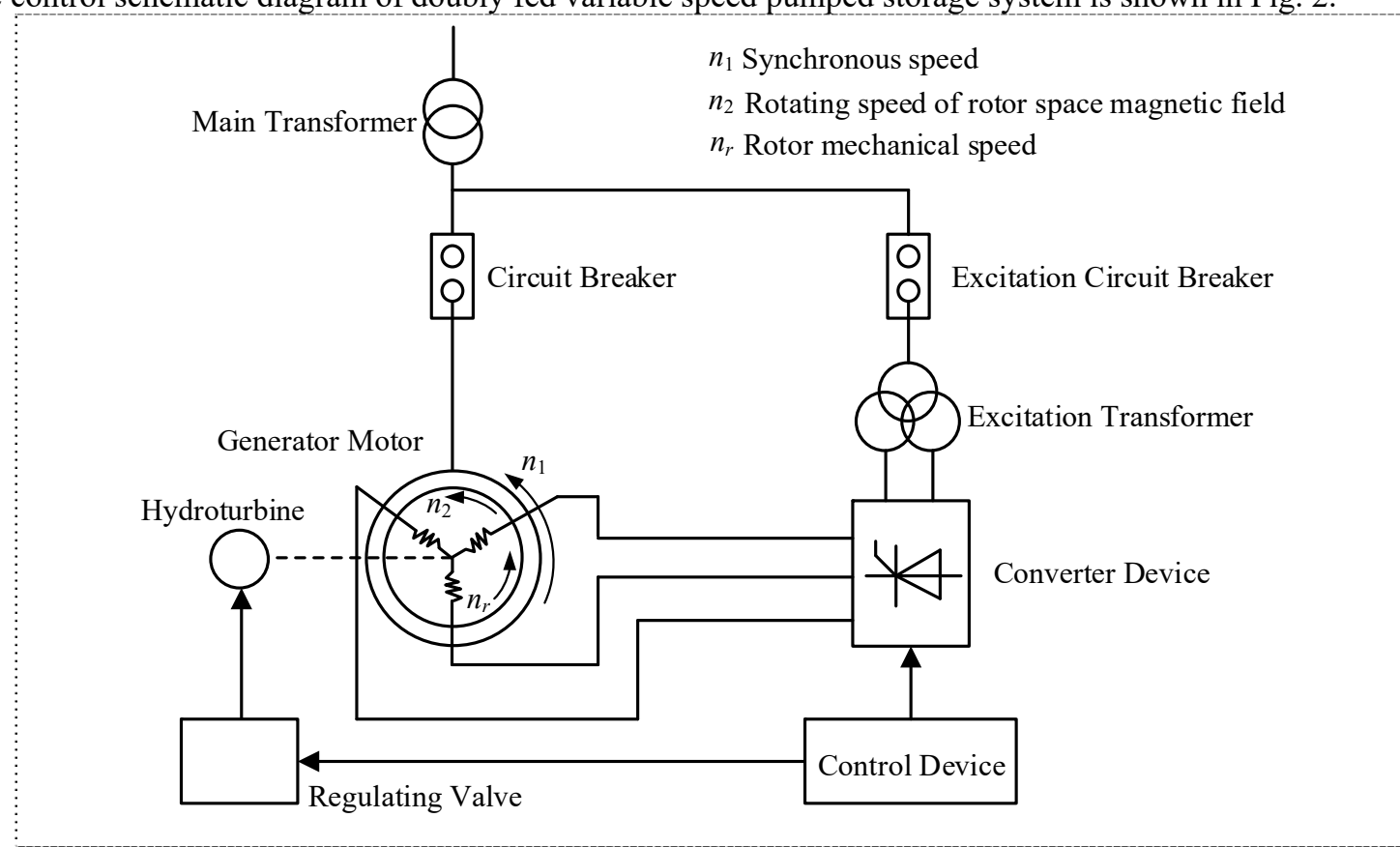

Figure 2. Control schematic diagram of doubly fed variable speed pumped storage system 
When the rotor coil with three-phase winding passes through three-phase alternating current, a rotating magnetic field will be generated around the rotor. If the rotating speed of the rotating magnetic field is $n_{2}$ and the mechanical speed of the rotor is $n_{r}$, then from the stator side, the speed $n_{1}$ of the rotor rotating magnetic field is

$$
n_{1}=n_{2}+n_{r}
$$

Therefore, when $n_{1}$ is the synchronous speed and keeps a constant value, adjusting $n_{2}$ can realize the regulation of $n_{r}$.

In power generation mode, the principle of DFIG is the same as that of doubly fed wind turbine. The operation state of doubly fed variable speed pumped storage unit depends on rotor speed and rotating magnetic field speed:

(1) Sub synchronous operation state: $n<n_{1}$, rotating magnetic field speed $n_{2}$ generated by current with slip frequency $f_{2}$ is the same as rotor speed.

(2) Super synchronous operation state: $n>n_{1}$, rotating magnetic field generated by current with slip frequency of $f_{2}$ The field speed $n_{2}$ is opposite to the rotor speed.

(3) Synchronous operation state: $n=n_{1}$, slip frequency $f_{2}=0$, the rotor is DC excitation, which is the same as ordinary synchronous generator. In the electromotive mode, the rotor series electromotive force speed regulation method can be used.

The excitation and speed regulation system of doubly fed variable speed pumped storage unit is a frequency converter composed of power electronic devices. Its advantages are that it can be used in high-voltage and high-power systems with high reliability, and can quickly control the current and suppress the overvoltage of the excitation system, which is conducive to the stable startup of the unit and the reduction of high-order harmonics. In the power generation mode, for different water heads, the optimal speed of generating output power is different. The optimal power output can be achieved by controlling the excitation frequency to adjust the speed.

\subsection{Full power variable speed pumped storage system}

The electrical connection diagram of the full power variable speed pumped storage system is shown in Fig 3. The unit adopts salient synchronous motor. The stator side is connected with the power grid through SFC, and the rotor side is connected with the turbine. The SFC capacity is not less than the maximum adjustable power of the system.

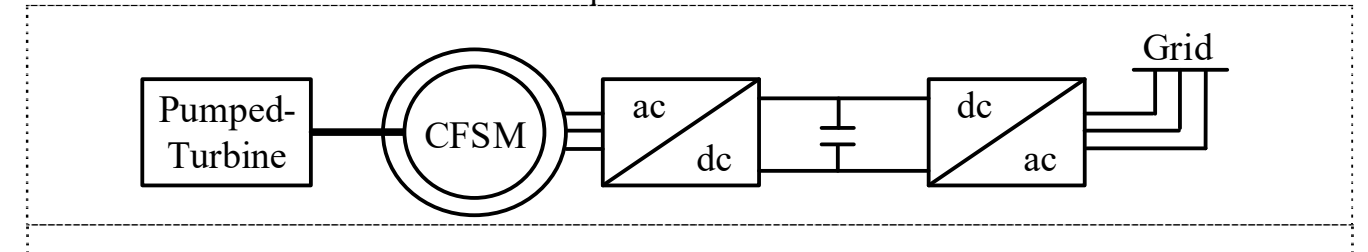

Figure 3. Connection diagram of full power variable speed pumped storage system.

Compared with the doubly fed variable speed pumped storage power station, the variable speed pumped storage power station based on full power variable speed and synchronous motor has been studied and paid attention to for the following reasons

(1) From the point of view of unit design, the rotor and start-up procedure of large capacity doubly fed variablespeed pumped storage unit composed of three-phase AC excited rotors are complex. Sometimes it is necessary to use pump turbine to drain water, which is difficult to meet the requirements of power grid. In addition, the complex rotor design is limited - limiting the speed increase to meet the optimum speed limit of the pump turbine. There are problems of additional loss, noise and reliability in multistage mechanical transmission system.

(2) From the point of view of electrical connection, the full power variable speed system can completely isolate the generator from the grid, and the motor speed range is wider, which can realize the complete speed regulation. At the same time, under the abnormal and fault state of power grid, the compatible operation ability of frequency converter is stronger. However, the speed regulation range of doubly fed variable speed unit is related to slip, so the speed regulation range is limited.

(3) From the point of view of power station transformation, the full power variable speed unit has certain advantages, whether it is to design and install a new power station or to refit an existing pumped storage power station. When the ordinary doubly fed variable speed unit is upgraded to full power unit, the main investment of pumped storage power station only increases by $2 \% \sim 4 \%$, but the performance is greatly improved. For example, the Grimsel 2 pumped storage power station in Switzerland (with a total installed capacity of $1125 \mathrm{MW}$ ) uses IGCT and other power electronic devices to convert the original fixed speed unit into a $100 \mathrm{MW}$ full power variable speed unit. The actual output can quickly follow the planned output, and good results have been achieved.

(4) From the perspective of the cost of frequency converter, the frequency converter of doubly fed variable speed technology only undertakes slip power, and the installed capacity only accounts for $20 \%-30 \%$ of the total installed capacity. It has been widely used because of the relatively low manufacturing cost. However, due to the rapid decline in the price of power electronic devices, the proportion of inverter in the overall project investment gradually decreases, and the advantages of less investment of doubly fed variable speed units are becoming less and more obvious.

(5) From the perspective of economic benefits, due to the price of new power electronic devices has been reduced again and again, the advantage of low investment of doubly fed variable speed units is becoming less and 
more obvious. At the same time, due to the variable speed and smooth adjustment of the unit, the friction loss of the turbine is reduced, the damage of the water flow to the turbine is reduced, and the vibration caused by resonance is reduced, thus the maintenance cycle of the unit is increased and the manpower, material and financial resources consumed in the maintenance are reduced. In a word, the full power inverter unit has a certain economy, whether it is designed, installed or refitted.

\section{Conclusion}

With the rapid development of control technology and the reduction of the price of power electronic devices, the development of variable speed pumped storage units has become an important trend. The variable speed pumped storage system with full power converter and its own characteristics will get more attention and engineering application. This is because full power variable speed pumped storage system has the advantages of large regulation range, simple system design and control, high operation efficiency, low maintenance cost and high reliability, which can make the small capacity unit more convenient to be converted into variable speed pumped storage power station.

\section{Acknowledgment}

This work was supported by the Research and Development Project of China Electric Power Research Institute Co., Ltd, i.e., Research on Key Technology of Variable Speed Operation of Static Inverter of Pumped Storage Unit (NY83-19-008).

\section{References}

1. M. Vitek, T. Kralik and J. Tuma. The role of pumped storage power plants in the power system operation. 2016 17th International Scientific Conference on Electric Power Engineering (EPE), Prague, 2016, pp. $1-5$.

2. D. Wang, et al. Developing and simulation research of the control model and control strategy of static frequency converter. 2012 Second International Conference on Intelligent System Design and Engineering Application, Sanya, Hainan, 2012, pp. 1032-1035.

3. Vitek M, Kralik T, Tuma J. The role of pumped storage power plants in the power system operation[C]. International Scientific Conference on Electric Power Engineering. 2016.

4. K. Desingu, R. Selvaraj, T. R. Chelliah and D. Khare. Effective utilization of parallel-connected megawatt three-level back-to-back power converters in variable speed pumped storage units. in IEEE Transactions on Industry Applications, vol. 55, no. 6, pp. 6414-6426, Nov.-Dec. 2019.

5. X. Jiang, R. He, P. Peng and X. Sun. Control strategy for variable speed pumped storage power station based on double-fed induction generator under different grid conditions. 2019 22nd International Conference on Electrical Machines and Systems (ICEMS), Harbin, China, 2019, pp. 1-6.

6. T. Wu et al. Modeling and control of variable speed DFIG pumped storage turbine based on RTDS. 2019 IEEE 3rd International Electrical and Energy Conference (CIEEC), Beijing, China, 2019, pp. 18841889.

7. G. Zhao, Q. Zhao and J. Ren. Output power modeling for dynamic behavior of doubly-fed variable-speed pumped storage power station. 2018 2nd IEEE Conference on Energy Internet and Energy System Integration (EI2), Beijing, 2018, pp. 1-61.

8. X. Song, B. G. Teshager, M. Han, Z. Meng, J. Xu and $X$. Wang. Stability and control of a grid integrated DFIM based variable speed pumped storage system. 2017 China International Electrical and Energy Conference (CIEEC), Beijing, 2017, pp. 163-168 